\title{
BERNHARD MATTES
}

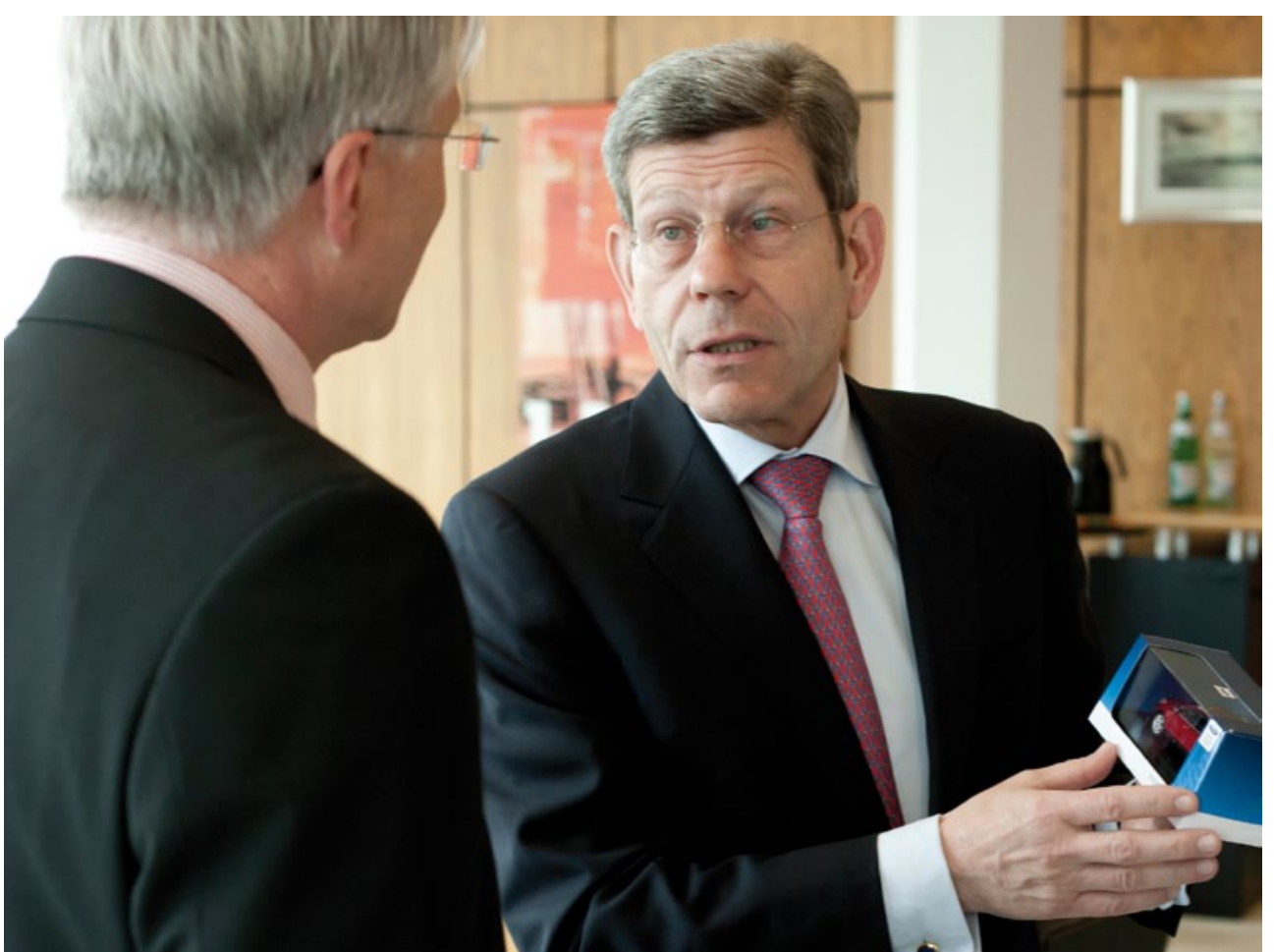

Begeistert, unprätentiös und offen spricht Bernd Mattes, Vorsitzender der Geschäftsführung der Ford-Werke $\mathrm{GmbH}$. Im Ford $17 \mathrm{~m}$, der legendären „Badewanne“, hat er zuletzt an einer Oldtimer-Rallye teilgenommen.

BILD ( ) Ford

\section{„WIR WERDEN NENNENSWERTE VOLUMINA SEHEN“}

Aus seinem Büro in Köln-Merkenich blickt Ford-Chef Bernhard Mattes auf das Entwicklungszentrum von Ford in Deutschland und ist zuversichtlich, wenn er sagt: „Wir wollen unseren Marktanteil in Deutschland von 7,3 Prozent halten und ausbauen. Dieses Jahr kommen noch etliche Fahrzeuge neu in unser Programm. " Trotz einer Marathonsitzung bis Mitternacht am Vorabend - Mattes sitzt im Verwaltungsrat des 1. FC Köln strahlt er beste Laune aus. Nach dem Rezept für diese Frische gefragt, kommt er auf Disziplin zu sprechen, die ihm wichtig zu sein scheint. Jedenfalls ist sein Schreibtisch ein Musterbeispiel an Ordnung. Und dass der begeisterte Jogger, Skifahrer und Tennisspieler mehr Kölsch trinkt, als sein Arzt in homöopathischer Dosierung empfehlen würde, kann man sich ebenfalls nicht vorstellen.

Mattes ist seit Februar 2006 Vice President Ford Customer Service Division bei Ford of Europe. Gleichzeitig ist er Vorsitzender der Geschäftsführung der Ford-Werke GmbH. Dieses Amt hat er bereits seit September 2002 inne und ist damit einer der dienstälteren Chefs in der deutschen Automobilindustrie. 1956 in Wolfsburg geboren - der Vater arbeitete dort in einer ManagerPosition - studiert Mattes zunächst Wirtschaftswissenschaften an der Universität Hohenheim. Von 1982 an sammelt er bei der BMW AG auf verschiedenen Vertriebspositionen wichtige Erfahrungen. 1999 wechselt Mattes zu Ford nach Köln, um die Position des Vorstands für Vertrieb und Marketing zu übernehmen.

\section{„FORD-KUNDEN SIND EIN GUTES PREIS-LEISTUNGS- VERHÄLTNIS GEWOHNT“}

Klar, dass Mattes beim Thema emissionsfreie Mobilität über den Ford Focus Electric spricht. Von den Chancen der E-Mobilität ist der Ford-Chef überzeugt: „Trotz erheblicher Kosten für die Speichermedien werden wir hier langfristig nennenswerte Volumina sehen. Das hängt natürlich vom Anschaffungspreis ab, Ford-Kunden sind ein gutes Preis-Leistungs-Verhältnis gewohnt. Wir sind auch sehr dafür, Anreize für große Flottenkunden zu schaffen, damit diese in elektrifizierte Fahrzeuge investieren.“ Bis 2020 sagt er einen Marktanteil von bis zu 25 Prozent der Gesamtnachfrage voraus, „davon der größte Teil Hybride“.

\section{„RUSSLAND WIRD DER GRÖSSTE EUROPÄISCHE MARKT“}

Mattes lässt noch eine Eigenschaft durchblicken: realistischen Optimismus. Man müsse anstreben, dort erfolgreich zu bleiben, wo man es schon ist. „Wir sind seit vielen Jahren Marktführer in England und in Europa immer noch die Nummer zwei und wollen das auch bleiben“, gibt er ein Beispiel. Wachstumspotenzial sieht Mattes im Osten und ist überzeugt, dass Russland Platzhirsch werden wird. Für die nächste Dekade prophezeit er dort über vier Millionen Einheiten und will sich von diesem Kuchen ein gutes Stück abschneiden. Optimismus eben! 